\title{
Comunicación
}

\section{SEROPREVALENCIA DE Brucella sp. EN BOVINOS CRIOLLOS DE CRIANZA EXTENSIVA DE LA PROVINCIA DE PARINACOCHAS, AYACUCHO}

\author{
Lesmes Valdivia P. ${ }^{1}$ y Hermelinda Rivera G. ${ }^{2}$
}

\section{SUMMARY}

\begin{abstract}
The objetive of the present study was to determine the seroprevalence of Brucella $s p$. in creole cattle of the province of Parinacochas, Ayacucho, Perú. Serum samples were collected from cows and heifers of 24 herds $(n=385)$ located in 4 districts (Chumpi, Coracora, Puyusca and Pullo), to detect antibodies against Brucella sp. by the Rose Bengal agglutination test. Seroreactor animals were not found indicating that the area is free of Brucella sp. infection or would have a prevalence less than $4.87 \%$. The results may be due to the effective surveillance programme conducted by the sanitary authorities on internal movement of animals, as well as the prevailing climatic conditions and breeding system, which may be adverse to Brucella sp.
\end{abstract}

Key words : creole cattle, Brucella sp., prevalence, antibodies, Rose Bengal

La brucelosis es causada por bacterias del género Brucella. Este género comprende 7 sub-especies conocidas como B. abortus, B. melitensis, B. suis, B. ovis, B. canis, B. neotomae y $B$. maris (Forbes y Tessaro, 1996; Samartino, 2001).

La brucelosis es prevalente a nivel mundial, pero en especial en los países en desarrollo (Acha y Szyfres, 1989; Gómez, 1993). En América Latina, la brucelosis ocasiona pérdidas económicas estimadas en 600 millones de dólares anuales; no sólo por las fallas reproductivas, sino también, por constituir una barrera para el comercio internacional de animales (FAO/OMS, 1986).
En el país existen estudios sobre la brucelosis bovina en las principales cuencas lecheras de Cajamarca, Lima, Arequipa, el valle del Mantaro, y en algunas zonas tropicales como Pucallpa, el Alto Mayo, y Tarapoto; con prevalencias que varían de 0 a menos del 1\% (Informe IAEA/FAO, 1999). Sin embargo, existe escasa información sobre la prevalencia de la brucelosis en bovinos criollos andinos a pesar de que estos animales constituyen el 86\% (3.8 millones) del total de la población bovina del país (INEI, 1995).

El departamento de Ayacucho concentra una población bovina de 302,859 ani-

\footnotetext{
1 Práctica privada

2 Laboratorio de Microbiología y Parasitología Veterinaria, FMV-UNMSM

3 E-mail: hriverag@vet.unmsm.edu.pe
} 
males. En 1972 poseía 345,475 cabezas de ganado, lo que significa una disminución de $12.4 \%$ (INEI, 1995). Es posible que la problemática social vivida en las décadas del '80 y '90 haya sido uno de los factores más importantes para esta disminución; sin embargo, las enfermedades infecciosas bacterianas, virales y parasitarias han podido ser los factores limitantes del desarrollo ganadero en esta área; y dentro de estas, la brucelosis es una de las enfermedades infecciosas de mayor importancia para la salud animal y salud pública (FAO/OMS, 1986).

La información sobre la prevalencia de brucelosis en la región andina es escasa, habiéndose reportado en el Valle del Mantaro una prevalencia de $0.3 \%$ (Cruz, 1996); pero no se dispone de datos de prevalencia en zonas como Parinacochas que posee 32,000 cabezas de ganado bovino. Es así que el objetivo del presente trabajo fue determinar la seroprevalencia de la Brucella sp. en bovinos criollos de crianza extensiva de la provincia de Parinacochas, la cual se encuentra al sur del departamento de Ayacucho, a una altitud promedio de 3,000 msnm.

Se trabajó con 4 de los 8 distritos (Chumpi, Coracora, Puyusca y Pullo), los cuales concentran el $78 \%$ de la población bovina. El área contiene una población de 25,502 bovinos de los cuales 14,534 son hembras (INEI, 2000). Se trabajó con hembras bovinas mayores de 18 meses (MINAG, 2000). Para determinar el tamaño muestral se utilizó la fórmula para estimar una proporción (Daniel, 1996). Al no existir estudios anteriores en la zona, se empleó la proporción 0.5 con la cual se obtiene el mayor tamaño muestral $(\mathrm{n}=385)$. Para estimar la prevalencia, el tamaño de la muestra se estratificó de acuerdo a la población de vientres bovinos de los 4 distritos.

Se obtuvieron muestras de sangre por punción de la vena yugular recolectadas en tubos al vacío de $10 \mathrm{ml}$. El suero fue separado mediante centrifugación, trasvasado a un vial y almacenado a $-20{ }^{\circ} \mathrm{C}$ hasta su análisis.
El periodo muestral fue de noviembre a diciembre del 2000.

Se utilizaron las pruebas de Rosa de Bengala y Elisa Indirecta para la detección de anticuerpos contra Brucella sp. La prueba de Rosa de Bengala se llevó a cabo según el Manual de Normas para las Pruebas de Diagnóstico y las Vacunas de la Oficina Internacional de Epizootias (OIE, 1992), y del $6^{\text {to }}$ Informe del Comité Mixto FAO/OMS de Expertos en Brucelosis (FAO/OMS, 1986). La prueba se realizó en el Laboratorio del Hospital de Apoyo de Coracora, Ayacucho, y las contramuestras se trabajaron en el Laboratorio de Virología de la Facultad de Medicina Veterinaria de la UNMSM (Lima), mediante la prueba de ELISA Indirecta con una sensibilidad y especificidad de $96.4 \mathrm{y}$ 96.3\%, respectivamente, y según el protocolo disponible en el laboratorio. En el análisis estadístico se utilizó la fórmula de prevalencia aparente, que evalúa los casos positivos sobre el total de muestras.

El diagnóstico de la brucelosis en el país es realizado mediante la prueba de aglutinación Rosa de Bengala o ELISA indirecta, como prueba tamiz, seguida por la prueba confirmatoria de Fijación de Complemento (MINAG, 2002). La prueba Rosa de Bengala es una prueba de campo de simple realización con una especificidad de $100 \%$ y una sensibilidad de 75\% (Corbel, 1991; FAO/ OMS, 1986; Tizard, 1995) y se recomienda para estudios de seroprevalencia en lugares donde no se practica la vacunación contra la brucelosis, como es el caso de Parinacochas.

Ninguno de los 385 sueros analizados por ambas pruebas presentaron anticuerpos aglutinantes, indicando que estos animales no tuvieron experiencia con la Brucella abortus, B. melitensis o B. suis. La ausencia de la brucelosis así como de la tuberculosis (Sánchez, 2002) en estos animales representan magníficas ventajas frente a otras áreas ganaderas donde ambas infecciones están presentes y constituyen permanentes amenazas para la salud animal y la salud pública. 
La mayoría de los animales muestreados fueron criollos, de rebaños pequeños, criados en forma extensiva sin o con poca tecnología, con excepción del distrito de Coracora, donde existen varios hatos lecheros mejorados de crianza semiextensiva. El pastoreo en áreas comunales y las ferias donde se realizan la compra-venta de bovinos y otras especies constituyen medios favorables para la difusión de enfermedades como la brucelosis. Sin embargo, la ausencia de reactores a Brucella sp. en los animales muestreados podría deberse a que esta enfermedad no ha ingresado a la provincia. Es probable que el movimiento nacional de bovinos, por estar sujeta al Programa Nacional de Control de la Brucelosis, y supervisada por las autoridades sanitarias del SENASA y el Ministerio de Agricultura, esté actuando como un adecuado filtro para la infección. Además, la cuenca lechera de Arequipa, zona relativamente cerca y de donde podrían provenir los animales, tiene una prevalencia de < $1 \%$ (López et al., 1995).

Información proporcionada por los campesinos no evidenció la existencia de problemas reproductivos como los abortos o retenciones de placenta, que son los signos clínicos más importantes de la brucelosis; constituyendo un argumento más que apoya la ausencia de la infección en los animales muestreados.

Se pudo concluir que la infección por Brucella sp. está ausente en los bovinos muestreados de los 4 distritos de la provincia de Parinacochas, Ayacucho (o de existir, tendría una prevalencia inferior a $4.87 \%$ ).

\section{Literatura Citada}

1. Acha, P.N.; B. Szyfres. 1989. Zoonosis y enfermedades transmisibles comunes al hombre y a los animales. $2^{\text {da }}$ ed. $p$ 1434. Organización Panamericana de la Salud. Washington.
2. Corbel, M.J. 1991. Brucelosis. En: Fertilidad e Infertilidad en la Práctica Veterinaria. Laing, J.A., Brinley Morgan, W.J., Wagner, W.C. (eds). $4^{\text {ta }}$ ed. p 201-236. Ed. Interamericana. España.

3. Daniel, W.M. 1996. Bioestadística: Base para el análisis de las ciencias de la salud. p 202-208. Uthea, Noriega Editores. México.

4. FAO/OMS. 1986. Comité Mixto de Expertos en Brucelosis. Sexto informe. Serie de Informes Técnicos 740. OMS. Ginebra. $149 \mathrm{p}$.

5. Forbes, L.B; S.V. Tessaro. 1996. Infection of cattle with Brucella abortus biovar 1 isolated from bison in Wood Buffalo National Park. Can. Vet. J. 37: 415-419.

6. Gómez, M.J. 1993. La brucelosis bovina, el enemigo de todos. El Cebú 269: 8-13.

7. Instituto Nacional de Estadística e Informática. INEI. 1995. III Censo Nacional Agropecuario: Resultados Definitivos, Departamento de Ayacucho. Tomo II. p 152-203. Dirección Técnica de Censos y Encuestas. Lima, Perú.

8. Instituto Nacional de Estadística e Informática. INEI. 2000. Conociendo Ayacucho. Lima-Perú. p 105-107. Dirección Técnica de Censos y Encuestas. Lima, Perú.

9. Informe Anual del Proyecto de Cooperación Técnica PER/5/023 de la Agencia Internacional de Energía Atómica (IAEA/FAO). 1999. p 15-18.

10. López, E.P.; L. Olivera; R. Perales; R. Rosadio. 1995. Vigilancia epidemiológica de la brucelosis bovina en la Cuenca Lechera de Arequipa. Rev. Inv. Pec. IVITA 7: 127-132.

11. Ministerio de Agricultura (MINAG). 2000. Dirección General de Sanidad Agraria SENASA. Decreto Supremo $\mathrm{N}^{\circ} 033-$ 2000-AG. Reglamento para el Control y Erradicación de la Brucelosis Bovina.

12. Ministerio de Agricultura (MINAG) 2002. Servicio Nacional de Sanidad Agraria SENASA. Dirección de Programas Zoosanitarios. Control y erradicación de brucelosis y tuberculosis bovina. Memoria Anual. p 43-45. 
13. Oficina Internacional de Epizootias (OIE). 1992. Suplemento al Manual de Normas para las Pruebas de Diagnóstico y las Vacunas para las Enfermedades de las Listas A y B de los Mamíferos, Pájaros y Abejas. $2^{\text {da }}$ ed., p 85-89. World Organization for Animal Health. París, Francia.

14. Samartino, L.E. 2001. Brucelosis en Latinoamérica: Situación actual y pers- pectivas de control. Rev. Inv. Vet. Perú, Suppl. 1: 1-5.

15. Sánchez, D.E. 2002. Prevalencia de la tuberculosis bovina en la provincia de Parinacochas, Ayacucho. Tesis de Médico Veterinario. Facultad de Medicina Veterinaria, Univ. Nacional Mayor de San Marcos. Lima, Perú.

16. Tizard, I. 1995. Inmunología Veterinaria. $4^{\text {ta }}$ ed. p 245-249. Ed. Interamericana. México. 